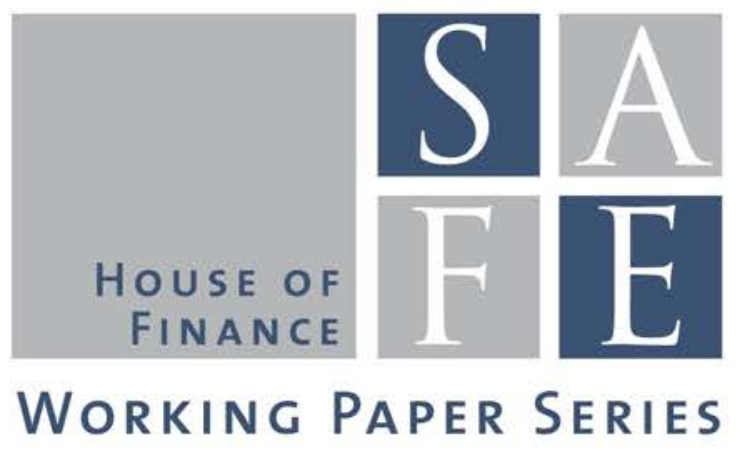

Vilen Lipatov - Alfons Weichenrieder

\title{
A Decentralization Theorem of Taxation
}

SAFE Working Paper No. 105

\section{SAFE I Sustainable Architecture for Finance in Europe}

A cooperation of the Center for Financial Studies and Goethe University Frankfurt 


\section{Non-Technical Summary}

In the EU, there are longstanding and continuing pressures towards a tax that is levied on the EU level to substitute for the present national contributions that are largely based on gross national income (GNI) of member states. In line with this, President of the EU Parliament Martin Schulz recently complained that the EU is "still stuck with an overly complex and outdated system full of exceptions and mostly made up by contributions from national budgets." The present paper discusses the conditions under which a transition to a genuine EU tax makes economic sense, starting from elementary principles of fiscal federalism.

The allocation of taxation rights is an enduring issue in fiscal federalism theory. A long-standing argument put forward in the literature is to assign benefit taxes and taxes on immobile tax bases to lower-level governments and to reserve the more mobile tax bases to the central level to avoid fiscal externalities that may occur if lower-tier governments are using mobile tax bases (Musgrave 1983; Oates 1999). An extensive taxonomy of possible spillover effects that may result from taxation of mobile tax bases by subnational governments has been provided by Gordon (1983).

The usual fiscal federalism framework, however, is somewhat different from the present European discussion. While a large literature in fiscal federalism is concerned about financing the subcentral provision of public goods, the present discussion is about financing the central budget by either a centralized tax or regional contributions levied by regional taxes.

The paper establishes the superiority of decentralized taxation compared to uniform central taxation for financing a central budget if spillover effects are absent and the size of the central budget is given. Later, we introduce spillover effects of regional taxes and discuss the amount of tax coordination this requires. We find that a system where there is coordination on the tax instrument used at decentralized levels plus centrally set regional contributions is superior to a centralized tax if spillover effects between regions do not depend on the intra-regional distribution of the tax burden. 


\title{
A Decentralization Theorem of Taxation*
}

\author{
Vilen Lipatov $^{\dagger}$ and Alfons Weichenrieder ${ }^{\ddagger}$ \\ May 2015
}

\begin{abstract}
In the EU there are longstanding and ongoing pressures towards a tax that is levied on the EU level to substitute for national contributions. We discuss conditions under which such a transition can make sense, starting from what we call a "decentralization theorem of taxation" that is analogous to Oates (1972) famous result that in the absence of spill-over effects and economies of scale decentralized public good provision weakly dominates central provision. We then drop assumptions that turn out to be unnecessary for this results. While spill-over effects of taxation may call for central rules for taxation, as long as spill-over effects do not depend on the intra-regional distribution of the tax burden, decentralized taxation plus tax coordination is found superior to a union-wide tax.

Keywords: fiscal federalism, taxing rights, decentralization theorem

JEL Classification: H21, H77
\end{abstract}

\section{Introduction}

In the EU, there are longstanding and continuing pressures towards a tax that is levied on the EU level to substitute for the present national contributions

*This paper is part of the research program of the Center "Sustainable Architecture for Finance in Europe" (S A F E) funded by the State of Hessen initiative for research, LOEWE. Project funding (\#2014-11531) is greatfully acknowledged.

† Goethe University Frankfurt and CESifo

${ }^{\ddagger}$ Goethe University Frankfurt, Vienna University of Business and Economics, and CESifo, corresponding author: e-mail: aw@em.uni-frankfurt.de, phone: (+49) 69 798-34789, address: Theodor-W.-Adorno-Platz 4, 60629 Frankfurt am Main, Germany 
that are largely based on gross national income (GNI) of member states. In line with this, President of the EU Parliament Martin Schulz recently complained that the EU is "still stuck with an overly complex and outdated system full of exceptions and mostly made up by contributions from national budgets." 1

An alternative to contributions coming from the national budgets would be to have a genuine EU tax, the revenue of which is handed to the EU by national governments. The present paper discusses the conditions under which such a transition makes economic sense, starting from elementary principles of fiscal federalism.

The allocation of taxation rights is an enduring issue in fiscal federalism theory. A long-standing argument put forward in the literature is to assign benefit taxes and taxes on immobile tax bases to lower-level governments and to reserve the more mobile tax bases to the central level to avoid fiscal externalities that may occur if lower-tier governments are using mobile tax bases (Musgrave 1983; Oates 1999). Conversely, an extensive taxonomy of possible spillover effects that may result from taxation of mobile tax bases by subnational governments has been provided by Gordon (1983). ${ }^{2}$ The usual fiscal federalism framework, however, is somewhat different from the present European discussion. While a large literature in fiscal federalism is concerned about financing the subcentral provision of public goods, the present discussion is about financing the central budget by either a centralized tax or regional contributions levied by regional taxes.

A classical contribution to fiscal federalism theory is Oates (1972) who proposes that in absence of spillover effects or economies of scale in the provision of a publicly provided good the lowest tier government should be in charge of providing the good. Oates' decentralization theorem provides an important benchmark for the allocation of responsibilities for the provision of public services when several levels of governments exist. Under the assumptions above, the decentralization theorem argues that responsibility should be given to the lowest level of government to cater possible taste heterogeneity among regions. Our paper stresses an analogy: we argue that tax bases that do not have spillover effects between regions of a federation or economies of scale in levying should be decentralized to allow optimal catering for regions'

\footnotetext{
${ }^{1}$ European Parliament, Press Release, 25 February 2014.

${ }^{2}$ Further related contributions include Inman and Rubinstein (1996) and Goodspeed (2000).
} 
heterogeneity. ${ }^{3}$

One assumption that is central to the derivation of Oates' theorem is that a government which decides on a specific service level can not differentiate the service level within its jurisdiction. This assumption has been criticized as empirically wrong; see Lockwood (2000; 2006, p. 34). At the same time, when it comes to taxation, there are usually strong constitutional restrictions that disallow regional differentiation and this is the perspective taken in this paper. ${ }^{4}$

The structure of the paper is as follows. In a first step we establish the superiority of decentralized taxation compared to uniform central taxation for financing a central budget if spillover effects are absent and the size of the central budget is given. Then we endogenize the size of the budget. Finally, we introduce spillover effects of regional taxes and discuss the amount of tax coordination this requires. We find that a system where there is coordination on the tax instrument used at decentralized levels plus centrally set regional contributions is superior to a centralized tax if spillover effects between regions do not depend on the intra-regional distribution of the tax burden. A final section concludes.

\section{A Decentralization Theorem with Fixed Spend- ing Needs}

We use $m=1 \ldots M$ to denote jurisdictions (regions or member states) within a union or federation and $j$ to denote the (immobile) individuals living in $m$, with $j=1 \ldots J_{m} .^{5}$

Definition 1 A tax instrument $n_{m}$ is the taxbase that together with a vector of individual contributions $\left\{C_{j, m}\right\}$ determines individual utilities $\left\{u_{j, m}\right\}$ for each jurisdiction $m$.

\footnotetext{
${ }^{3}$ There are verbal discussions that hypothesize on the applicability of Oates' decentralization theorem to taxes (e.g. McLure and Martinez-Vazquez 2004), but, to the best of our knowledge, no formal treatment of this problem.

${ }^{4}$ For example, when Germany introduced a surcharge to finance the accession of East Germany in the 1990s the tax was introduced in the West as well as in the East. Tresch (2002, p. 839) emphasizes the role of U.S. constitutional constraints for differentiating taxes across U.S. states.

${ }^{5}$ The paper uses union and federation as synonyms. Similarly, we make no distinctions between region and member state.
} 
Clearly, by utilities we mean indirect utility levels achieved for given direct utility functions of individuals and the tax instrument in use. The instrument affects individual utilities both directly, through monetary contributions, and indirectly, through behavioral response and associated deadweight loss. Different instruments cause different labor supply reaction, tax avoidance and evasion, and have also diæerent administrative costs. Hence, the same instrument applied in diæerent member states may cause different behavioral responses.

Assumption 1 (Exogenous revenue requirement). The central level of the union is facing a certain level of (exogenous) spending needs that amount to $G$, which is independent of the tax instruments used.

Assumption 2 (Uniform tax policy at the decision level). Assume there are $N$ possible tax instruments that can be used, public policy has to select at most one of these at the relevant decision level. The decision level may be the central level or the individual jurisdiction.

The assumption of just one tax instrument per decision level is less restrictive as it seems, as the each tax instrument may be conceived as a combination of elementary tax instruments. Decentralized taxation means there are up to $M$ different tax instruments actually used, while central taxation implements a uniform tax instrument. This is the essential implication of the assumption.

Assumption 3 (No spillover). Tax instruments used in one jurisdiction have no spillover on utility in other jurisdictions. The utility $u_{j, m}$ of individual $j$ in member state $m$ of the union depends (negatively) on the contribution $C_{j, m}$ she has to make, (positively) on the amount of public good $G$, and additionally on the tax instrument $u_{j, m}=$ $u_{j, m}\left(C_{j, m}, G, n_{m}\right)$. A certain amount of tax revenue $C$ may have a different utility loss depending on the tax instrument used because the excess burden and/or compliance cost of taxation differ among instruments.

Our utility function $u: \mathbb{R}_{+}^{2} \times \mathcal{S} \rightarrow \mathbb{R}$ maps the sets of possible tax contributions $C$, amounts of public good $G$, and possible tax instruments (which is a set of all tax bases) $n$ into the real line. Note that we assume that such a function exists, that is the effect of any tax base on individual utility can 
be computed once the use of the instrument is announced and individuals have adjusted their behavior. We also assume that it is strictly decreasing and continuously differentiable in the first argument and increasing and continuously differentiable in the second argument.

Since $G$ is assumed constant, we can drop it from the utility function below. The utility may vary individually and across jurisdictions. It is a function of the tax instrument. Across jurisdictions, differing tax compliance and tax morale may suggest different optimal tax instruments.

Consider two possible ways to raise the amount $G$. First, the tax instrument may be decided on centrally and the same instrument is applied to all individuals irrespective of the member state they are living in. That is, $n_{m}=n \forall m$. Second, the taxation decision may be decentralized. On the central level, national contributions $C_{m}$ are set which have to be levied by personal contributions, in total $\sum_{j} C_{j, m}=C_{m}$. National contributions have to conform with the revenue requirement $\sum_{m} C_{m} \geq G$. The assumed utility functions ensure that this constraint is always binding.

At the level of the jurisdiction, we assume a local welfare function $W_{m}=$ $W_{m}\left(u_{1, m}, \ldots, u_{J_{m}, m}\right)$. To avoid inconsistencies between local and central decisions, we make the following assumption:

Assumption 4 (Non-paternalistic union). The central welfare is an increasing function of local welfare: $\Omega=\Omega\left(W_{1}, \ldots, W_{m}\right)$.

The optimization problem of the central level can be written as follows.

$$
\begin{array}{cc} 
& \max _{n, C_{j, m}} \Omega \\
\text { s.t. } \quad & \sum_{m=1}^{M} C_{m}=G
\end{array}
$$

Conversely, the optimization problem of the individual jurisdiction $m$ can be written as follows.

$$
\begin{array}{ll} 
& \max _{\substack{n_{m}, C_{j, m} \\
\text { s.t. }}} W_{m} \\
\sum_{j} C_{j, m}=C_{m}
\end{array}
$$


Union-wide welfare in this case is $\Omega=\Omega\left(W_{1}^{*}, \ldots, W_{m}^{*}\right)$, where the $W_{j}^{*}$ represent the regions' optimized values of local welfare.

Proposition 1 Under assumptions 1-4, decentralization of taxation is weakly welfare improving compared to centralized solution.

Proof. Let $n^{*} \in \arg \max _{n} \Omega$ in the centralized solution with corresponding contributions $\left(C_{1, m}^{*}, \ldots, C_{J_{m}, m}^{*}\right)$ for each jurisdiction $m$. In a decentralized solution the central level may set the same vector of regional contributions $C^{*}=\left(C_{1}^{*}, \ldots, C_{M}^{*}\right)$ and each jurisdiction $m$ decides on its tax instrument $n_{m}$. Since $n^{*}$ is feasible for the vector of contributions given to the local government, it must be that the welfare under local welfare maximizing policy $n_{m}$ is at least as high as the welfare under uniform policy maximizing global welfare $n^{*}, W_{m}\left(C_{m}^{*}, n_{m}\right) \geq W_{m}\left(C_{m}^{*}, n^{*}\right) \forall m$. Since none of the arguments of $\Omega$ is lower under decentralized optimization, $\Omega$ is weakly higher under decentralization.

This is a very general result, since we do not even need to assume that the instruments may differ as to the extent of the excess burden that they impose on the residents. The superiority of decentralization may be driven purely by heterogeneity of individual preferences and the fact that regional governments may accommodate those better than the central government bound to use a uniform policy everywhere. Preference heterogeneity may result from different behavioral responses to different types of taxes across regions or from different types of aversions against certain taxes. For example, different taxes imply a different intrusion into privacy by auhorities and this intrusion may be evaluated differently. Different regions may also have different distributional preferences embodied in local welfare functions.

\section{Endogenous $G$}

To fix ideas about how our result is affected by relaxing the exogenous government spending assumption, we consider the simplest textbook model of public good provision. To facilitate presentation, we consider a two-persontwo-country model, whereby we do not impose any ordering on preferences except for that in each country, (i) one person likes the public good more than the other and (ii) no person has the same preference for the public good. Formally, for each country $i=A, B$, we have $u_{G}^{i, h}(C, G, n)>u_{G}^{i, l}(C, G, n)$. Suppose further there is a simple linear transformation technology for producing 
the public good and all the welfare functions are purely utilitarian with equal weights. While this is a more specific assumption, it is obviously compatible with Assumption 4. Then, the central government that can differentiate contributions between $h$ and $l$ types, but not across countries, solves

$$
\begin{array}{ll} 
& \max _{C_{j}, n} \sum_{i, j} u^{i, j}\left(C_{j}, G, n\right) \\
\text { s.t. }: & 2\left(C_{h}+C_{l}\right)=G
\end{array}
$$

Instead of maximizing directly over the tax instruments, consider first choosing the pair of contributions that solves the problem above for given $n$. The FOC for each $j \in\{h, l\}$ is then

$$
\sum_{i} u_{C}^{i, j}\left(C_{j}, G\right)+2 \sum_{j} u_{G}^{i, j}\left(C_{j}, G\right)=0,
$$

which is of course a version of the Samuelson rule. The decentralized problem for fixed $n$ is

$$
\begin{aligned}
& \max _{C_{i, h}, C_{i, l}} \sum_{j} u^{i, j}\left(C_{i, j}, G\right) \\
\text { s.t. }: & \sum_{i, j} C_{i, j}=G
\end{aligned}
$$

with corresponding FOCs

$$
\sum_{j} u_{C}^{i, j}\left(C_{i, j}, G\right)=-\sum_{j} u_{G}^{i, j}\left(C_{i, j}, G\right)
$$

Since $C_{A, j} \neq C_{B, j}$, one force driving the differences in the two solutions is the same as the one in Proposition 1: the member states can accommodate the preferences better than the central government. However, with endogenous public good provision, there is a second force that goes against decentralization: public goods are underprovided, because the government of each member state decides on its level without considering the externality it has on the other member state.

If $n$ is not fixed, but allowed to be chosen optimally, this acts as an extra force that speaks for decentralization: not only contributions, but also the behavioral responses can be better accounted for by local governments (member states). However, this does not directly affect the underprovision 
channel, as the incentive to free-ride is there even with the instruments that are optimally tailored for local behavioral responses.

To circumvent the problem of underprovision, we can design the distribution of decision making rights in the following way: in the decentralized solution, the member states decide on the distribution of contributions and the tax instrument to be used, whereas the central government decides on the sum of contributions. Call this mechanism $\mathcal{M}$. The resulting decentralized solution can be represented by the subgame perfect equilibrium of a sequential game whereby the central government sets the level of the public good and contributions for each member state, the member states set individual contributions. We present a constructive approach to deriving equilibrium under such a mechanism in Appendix A. This mechanism actually resembles the current setting in the EU where the member states set their taxes independently, but are obliged to transfer a certain contribution to the European budget.

A member state $i$ 's problem can now be written as

$$
\begin{aligned}
& \max _{C_{i, h}, C_{i, l}, n_{i}} \sum_{j} u^{i, j}\left(C_{i, j}, G, n_{i}\right) \\
\text { s.t. }: & \sum_{j} C_{i, j}=C_{i}, n_{i} \in \mathcal{S}
\end{aligned}
$$

with corresponding FOCs

$$
u_{C}^{i, h}\left(C_{i, j}, G\right)=u_{C}^{i, l}\left(C_{i, j}, G\right)
$$

for given $n_{i}$. The optimal solution is then obtained by choosing the maximal welfare across the discrete set of instruments (differential calculus is not applicable here). Thus, the central government's problem under the mechanism $\mathcal{M}$ can be written as follows:

$$
\begin{aligned}
& \max _{C_{i, j}} \sum_{i, j} u^{i, j}\left(C_{i, j}, G, n_{i}^{*}\right) \\
\text { s.t. }: & \sum_{i, j} C_{i, j}=G .
\end{aligned}
$$

and subject to (5) and $n_{i}^{*} \in \arg \max _{n_{i} \in \mathcal{S}} \sum_{j} u^{i, j}\left(C_{i, j}, G, n_{i}\right)$. Note that the central government can choose $\left\{C_{i, j}\right\}$ directly in this formulation once it respects the constraints listed. The desired allocation is then implemented by the mechanism $\mathcal{M}$ whereby the central government prescribes $\left\{C_{i}\right\}$ only. 
Compare this with the first best in which central government has all the instruments without restriction:

$$
\begin{aligned}
& \max _{C_{i, j}, n_{i}} \sum_{i, j} u^{i, j}\left(C_{i, j}, G, n_{i}\right) \\
\text { s.t. } & : \quad \sum_{i, j} C_{i, j}=G .
\end{aligned}
$$

The FOCs are

$$
u_{C}^{i, j}\left(C_{i, j}, G\right)+\sum_{i, j} u_{G}^{i, j}\left(C_{i, j}, G\right)=0 .
$$

Because the constraint (5) is implied by (6), the two problems are equivalent (abstracting from $n_{i}$, the $\mathcal{M}$-problem is the same as the first best problem with additional restriction (5), but this restriction is not binding, which gives us equivalence). Showing that the member states and the first best problem will choose the same $n_{i}^{*}$ is a trifle less straightforward. Suppose the first best solution involves $n_{i}^{o} \notin \arg \max _{n_{i} \in \mathcal{S}} \sum_{j} u^{i, j}\left(C_{i, j}, G, n_{i}\right)$. Then the central government with full set of instruments could choose $n_{i}^{*}$, raise the welfare in region $i$ without changing it in the other region and without violating the feasibility constraint. But this contradicts the assumption that $n_{i}^{o}$ solves the first-best problem, QED.

Thus, the setting $\mathcal{M}$ is welfare superior to the setting in which the central governments chooses each contribution, but is constrained to set the same contributions for the same type of agents living in two different member states. This allows us to formulate the following refinement of proposition 1 :

Proposition 2 Under assumptions 2-4, decentralization of taxation in the sense of arrangement $\mathcal{M}$ is weakly welfare improving compared to centralized solution.

Proof. The proof follows from the discussion above.

\section{Spillovers}

The no spillover assumption seems crucial in our setup. However, in the following we show that not any type of externality destroys the results of propositions 1 and 2 .

For simplicity, we stay in the two by two framework and keep the amount of public goods exogenous (so we can drop $G$ from the arguments of the 
utility function, again). However, we do not rule out that the outcome in one member state is dependent on the outcome in another member state. Formally, $u^{i, j}=u^{i, j}\left(C_{i, j}, C_{-i}, n_{i}\right)$, where $C_{-i}$ conventionally stands for the aggregate contributions in the member state other than $i$. A positive externality of another member state contribution would be then represented by $u_{2}^{i, j}>0$, where with the subscript we denote a partial derivative with respect to the corresponding argument. This could be the case of competition for mobile resource whereby higher contribution of your neighbor means that the business or highly qualified workers will want to escape to your state. To the contrary, a negative externality $u_{2}^{i, j}<0$ could result from the resources escaping from your neighbor to a third country, depriving your state from e.g. nice market or supplier or resort.

Note that in a first step we assume that the method of raising the revenue $C_{-i}$ is irrelevant, that is the utility $u^{i, j}$ does not directly depend on $n_{-i}$, the instrument (tax base) used in the member state $-i$. We will drop this assumption in the next step, but for the moment we make

Assumption 3' Tax instruments used in one jurisdiction have no spillover on utility in other jurisdictions other than via aggregate tax revenue collected in this jurisdiction.

The restricted centralized problem can be written in the same way as (3), but the FOC is now

$$
u_{1}^{A, h}\left(C_{h}\right)-u_{1}^{A, l}\left(G / 2-C_{h}\right)+u_{1}^{B, h}\left(C_{h}\right)-u_{1}^{B, l}\left(G / 2-C_{h}\right)=0,
$$

where we slightly abused notation dropping the second argument, because it is uniformly equal to $G / 2 .^{6}$

Consider the mechanism $\mathcal{M}$. The best response of the member state $i$ to the total contribution requirement solves the problem (4) with the FOC for each $i \in\{A, B\}$ defined by

$$
u_{1}^{i, h}\left(C_{i, h}, C_{-i}\right)=u_{1}^{i, l}\left(C_{i}-C_{i, h}, C_{-i}\right) .
$$

The central government's first move is then a solution to

$$
\begin{aligned}
& \max _{C_{i, j}} \sum_{i, j} u^{i, j}\left(C_{i, j}, C_{-i}, n_{i}^{*}\right) \\
\text { s.t. } \quad & \quad \sum_{i, j} C_{i, j}=G
\end{aligned}
$$

\footnotetext{
${ }^{6}$ This comes from combining uniformity and feasibility restrictions into $2\left(C_{h}+C_{l}\right)=G$ so that $C_{-i} \equiv G / 2$.
} 
and subject to $(7)$ and $n_{i}^{*} \in \arg \max _{n_{i} \in \mathcal{S}} \sum_{j} u^{i, j}\left(C_{i, j}, C_{-i}, b\left(n_{i}\right)\right)$.

We can compare this to the first best, which is a solution to the problem

$$
\begin{aligned}
& \max _{C_{i, j}, n_{i}} \sum_{i, j} u^{i, j}\left(C_{i, j}, C_{-i}, n_{i}\right) \\
\text { s.t. } & : \sum_{i, j} C_{i, j}=G .
\end{aligned}
$$

Inspecting the two solutions, we can establish their equivalence, which allows us to formulate our final proposition:

Proposition 3 Under assumptions 2, 3' and 4, decentralization of taxation in the sense of arrangement $\mathcal{M}$ is weakly welfare improving compared to the centralized solution.

Proof. The proof is left to Appendix B.

The intuition behind this surprising result is fairy simple. In presence of aggregate (state) externalities, the superiority of decentralized setting $\mathcal{M}$ is preserved, because the central government determining aggregate state contributions can successfully internalize these externalities. The state governments only determine the distribution of the contribution (or tax burden) in the population without an opportunity to engage in tax competition.

Clearly, the same is not true if externalities depend on the distribution of contributions. Perhaps more importantly, Proposition 3 does not hold in a setting where the choice of tax base for fixed tax revenue affects the utility of individuals in another member state.

To illustrate the last point, suppose the utility is of the form $u^{i, j}\left(C_{i, j}, C_{-i}, b\left(n_{i}, n_{-i}\right)\right)$, where the function $b$ now maps not only the set of tax instrument in own region, but also the one in other regions, into the input of utility function. The restricted centralized problem is (as before, we slightly abused notation dropping the second argument, because it is uniformly equal to $G / 2$.)

$$
\max _{C_{h}, C_{l}, n} \sum_{i}\left(u^{i, h}\left(C_{h}, b(n)\right)+u^{i, l}\left(G / 2-C_{h}, b(n)\right)\right)
$$

with associated FOC

$$
\sum_{i}\left(u_{C}^{i, h}\left(C_{h}, b(n)\right)-u_{C}^{i, l}\left(G / 2-C_{h}, b(n)\right)\right)=0
$$


and the condition that $n^{*} \in \arg \max _{n \in \mathcal{S}} \sum_{i}\left(u^{i, h}\left(C_{h}, b(n)\right)+u^{i, l}\left(G / 2-C_{h}, b(n)\right)\right)$.

Under mechanism $\mathcal{M}$, the member state $i$ chooses tax instruments and individual contributions to solve

$$
\max _{C_{i, h}, C_{i, l}, n_{i}}\left(u^{i, h}\left(C_{h}, b\left(n_{i}, n_{-i}\right)\right)+u^{i, l}\left(G / 2-C_{h}, b\left(n_{i}, n_{-i}\right)\right)\right)
$$

with corresponding FOC

$$
u_{C}^{i, h}\left(C_{h}, b\left(n_{i}, n_{-i}\right)\right)-u_{C}^{i, l}\left(G / 2-C_{h}, b\left(n_{i}, n_{-i}\right)=0\right.
$$

and the condition $n_{i}^{*} \in \arg \max _{n_{i} \in \mathcal{S}}\left(u^{i, h}\left(C_{h}, b\left(n_{i}, n_{-i}\right)\right)+u^{i, l}\left(G / 2-C_{h}, b\left(n_{i}, n_{-i}\right)\right)\right)$.

Whereas on the contribution margin our mechanism is superior to the centralized solution (it equalizes marginal utilities in each member state rather than in the union on average), the choice of instrument (tax base) may only accidentally happen to be optimal. The latter happens because our mechanism is unable to internalize the externality caused by the decentralized choice of tax base: fixing overall contribution levels does not alleviate the problem. Thus, any policy introducing an EU-wide tax faces a clear trade-off between gains of harmonizing tax base and losses stemming from impossibility to levy taxes that fit local preferences best. Consequently, limiting the choice of the member states to the set of tax bases that have least interstate spillovers would minimize the negative effects of decentralization.

Taken to extreme, the EU might want to prescribe which exact tax base each member state should use and leave the distribution of the contributions within this tax base at the disposable of the national government. This would restore efficiency in the absence of individual interstate externalities. Formally, consider mechanism $\mathcal{N}$ : the member states decide on the distribution of contributions, whereas the central government decides on the sum of contributions for each member state and the tax instrument each member state is allowed to use. ${ }^{7}$ Under this mechanism, the best responses of the state governments are still defined by (7), whereas the central government

\footnotetext{
${ }^{7}$ It may seem that an instrument (taxbase) and the sum of contributions are suffcient to determine the tax incidence once the individual preferences are known. This is, however, only true in the world where all taxes are e.g. linear or lump-sum. The real world is not like that: there are different ways to collect the same amount of revenue from the same tax base. Consider e.g. nonlinear income tax, whereby there are infinitely many alternatives to raise the same revenue from the same set of incomes. Another example is VAT whereby different goods and services may be exempted and others taxed at reduced rates.
} 
solves

$$
\begin{aligned}
& \max _{C_{i, j}, n_{i}} \sum_{i, j} u^{i, j}\left(C_{i, j}, C_{-i}, n_{i}\right) \\
\text { s.t. } & : \quad \sum_{i, j} C_{i, j}=G
\end{aligned}
$$

and subject to (7). The proof of the fact that solution to this problem is equivalent to the first best solution is identical to the one used in proposition 3 with the exception that we do not have to care about tax instruments that now may not differ between the two formulations by construction. We can summarize this result in the following corollary to proposition 3 :

Corollary 1 Under assumptions 2 and 4, decentralization of taxation in the sense of arrangement $\mathcal{N}$ is weakly welfare improving compared to centralized solution.

\section{Conclusions}

The above analysis makes a simple point. Since centralized taxation implies uniform taxes across the union or federation, decentralization of taxation can better cater to differences in behavioral reactions to taxes, differences in regional redistributive preferencs, and different attitudes towards administrative issues. Clearly, spillover effects of regional taxation may have to be weighed off. The importance of fiscal externalities is reduced, however, if the revenues from decentralized taxes have to be handed to the central level that sets the total revenue requirement in each region. If suboptimal regional decisions prevail, they are likely to result from recurse to taxes that are optimal from a local perspective, but suboptimal from a union-wide welfare function. In this case, however, the optimal response may be to restrict the regional choice of tax instruments rather than to centralize taxation altogether. This possibility becomes a certainty whenever the spillover effects do not depend on the intra-regional distribution of the tax burden. We believe that this has interesting implications for the current discussion about a European tax to finance the EU budget. Decentralized taxation to fund the central budget is preferable to a central tax is spillover of taxation are absent. Even in the case of spillovers there is a strong case for tax coordination instead of uniform taxation. 


\section{References}

[1] Goodspeed, T.J. (2000), Tax Structure in a Federation, Journal of Public Economics 75, 493-506.

[2] Gordon, R.H. (1983), An Optimal Taxation Approach to Fiscal Federalism, Quarterly Journal of Economics 98, 567-586.

[3] Inman, P.I. and Rubinfeld, D.L. (1996), Designing Tax Policy in Federalist Countries: An Overview, Journal of Public Economics 60, 307-334.

[4] Lockwood, B. (2002), Distributive Politics and the Cost of Centralization, Review of Economic Studies 69, 313-337.

[5] Lockwood, B. (2006), The Political Economy of Decentralization, in: E. Ahmad and G. Brosio (eds.), Handbook of Fiscal Federalism, Cheltenham, Edward Elgar, 33-60.

[6] McLure, C. and Martinez-Vazquez, J. (2004), The Assignment of Revenues and Expenditures in Intergovernmental Fiscal Relations, The World Bank, Washington D.C.

[7] Musgrave, R.A. (1983), Who Should Tax, Where and What?, In: Charles E. McLure, Jr., ed. Tax Assignment in Federal Countries. Canberra: Centre for Research on Federal Financial Relations.

[8] Oates, W. (1972), Fiscal Federalismus. New York, Harcourt Brace Jovanovich.

[9] Tresch, R.W. (2002), Public Finance: A Normative Theory, 2nd edition, San Diego and London, Academic Press.

\section{Appendix A}

Here we explicitly state the conditions that define subgame perfect equilib-

rium arising under mechanism $\mathcal{M}$. Solution to the problem (4) defines best responses

$$
C_{i, h}=R_{i}\left(C_{A}, C_{B}\right), C_{i, l}=C_{i}-R_{i}\left(C_{A}, C_{B}\right)
$$


the central government takes this response into account while solving

$$
\begin{aligned}
& \max _{C_{A}, C_{B}} \sum_{i}\left(u^{i, h}\left(R_{i}\left(C_{A}, C_{B}\right), G\right)+u^{i, l}\left(C_{i}-R_{i}\left(C_{A}, C_{B}\right), G\right)\right) \\
\text { s.t. } & : \quad \sum_{i} C_{i} \leq G
\end{aligned}
$$

The FOC for the total contribution in member state $\mathrm{A}$ is

$$
\begin{gathered}
R_{A}^{\prime}\left(C_{A}\right) u_{C}^{A, h}\left(R_{A}\left(C_{A}, C_{B}\right), G\right)+u_{G}^{A, h}\left(R_{A}\left(C_{A}, C_{B}\right), G\right) \\
+\left(1-R_{A}^{\prime}\left(C_{A}\right)\right) u_{C}^{A, l}\left(C_{A}-R_{A}\left(C_{A}, C_{B}\right), G\right) \\
+u_{G}^{A, l}\left(C_{A}-R_{A}\left(C_{A}, C_{B}\right), G\right)+R_{B}^{\prime}\left(C_{A}\right) u_{C}^{B, h}\left(R_{B}\left(C_{A}, C_{B}\right), G\right) \\
-R_{B}^{\prime}\left(C_{A}\right) u_{C}^{B, l}\left(C_{B}-R_{B}\left(C_{A}, C_{B}\right), G\right) \\
+u_{G}^{B, h}\left(R_{B}\left(C_{A}, C_{B}\right), G\right)+u_{G}^{B, l}\left(C_{B}-R_{B}\left(C_{A}, C_{B}\right), G\right)=0
\end{gathered}
$$

with a symmetric expression for the member state B.

\section{Appendix B}

The solution to the first-best problem (8) for given $\left\{n_{i}\right\}$ is defined by the FOCs

$$
\begin{aligned}
& u^{A, h}\left(C_{A, h}, G-C_{A, h}-C_{A, l}\right)+u^{A, l}\left(C_{A, l}, G-C_{A, h}-C_{A, l}\right) \\
& +u^{B, h}\left(C_{B, h}, C_{A, h}+C_{A, l}\right)+u^{B, l}\left(G-C_{B, h}-C_{A, h}-C_{A, l}, C_{A, h}+C_{A, l}\right) \\
& \quad C_{A, h} \quad: \quad u_{1}^{A, h}\left(C_{A, h}, G-C_{A, h}-C_{A, l}\right)-u_{2}^{A, h}\left(C_{A, h}, G-C_{A, h}-C_{A, l}\right) \\
& \quad-u_{2}^{A, l}\left(C_{A, l}, G-C_{A, h}-C_{A, l}\right)+u_{2}^{B, h}\left(C_{B, h}, C_{A, h}+C_{A, l}\right) \\
& \quad-u_{1}^{B, l}\left(G-C_{B, h}-C_{A, h}-C_{A, l}, C_{A, h}+C_{A, l}\right)+u_{2}^{B, l}\left(G-C_{B, h}-C_{A, h}-C_{A, l}, C_{A, h}+C_{A, l}\right), \\
& \quad \quad \quad-u_{2}^{A, h}\left(C_{A, h}, G-C_{A, h}-C_{A, l}\right)+u_{1}^{A, l}\left(C_{A, l}, G-C_{A, h}-C_{A, l}\right) \\
& \quad-u_{2}^{A, l}\left(C_{A, l}, G-C_{A, h}-C_{A, l}\right)+u_{2}^{B, h}\left(C_{B, h}, C_{A, h}+C_{A, l}\right) \\
& \quad-u_{1}^{B, l}\left(G-C_{B, h}-C_{A, h}-C_{A, l}, C_{A, h}+C_{A, l}\right)+u_{2}^{B, l}\left(G-C_{B, h}-C_{A, h}-C_{A, l}, C_{A, h}+C_{A, l}\right) \\
& C_{B, h}: u_{1}^{B, h}\left(C_{B, h}, C_{A, h}+C_{A, l}\right)-u_{1}^{B, l}\left(G-C_{B, h}-C_{A, h}-C_{A, l}, C_{A, h}+C_{A, l}\right)=0
\end{aligned}
$$


From the last line, we can immediately see that the condition (7) for $i=B$ is implied by the first best solution. To see this for $i=A$, simply subtract the first condition from the second. The proof of non-existence of $n_{i}^{o} \notin \arg \max _{n_{i} \in \mathcal{S}} \sum_{j} u^{i, j}\left(C_{i, j}, G, b\left(n_{i}\right)\right)$ that solves the first best problem is identical to the previous section. Therefore, we receive equivalence of the equilibrium induced by mechanism $\mathcal{M}$ and the first best. 


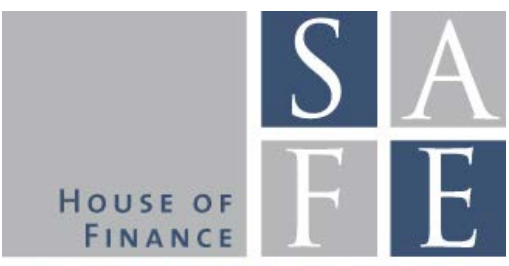

WORKING PAPER SERIES

\section{Recent Issues}

No. 104 Sascha Baghestanian, Baptiste Massenot

No. 103 Massimiliano Caporin, Loriana Pelizzon, Francesco Ravazzolo, Roberto Rigobon

No. 102 Iñaki Aldasoro, Iván Alves

No.101 Marcel Grupp

No. $100 \quad$ Marcel Grupp

No. 99 Marcel Grupp, Christian Rauch, Marc Umber, Uwe Walz

No. 98 Tobias Niedrig, Helmut Gründl

No. 97 Tobias Niedrig

No.96 Jens-Hinrich Binder

No. 95 Loriana Pelizzon, Marti G. Subrahmanyam, Davide Tomio, Jun Uno

No. 94 Claudia Lambert, Felix Noth, Ulrich Schüwer

No. 93 Shafik Hebous, Tom Zimmermann
Predictably Irrational: Gambling for Resurrection in Experimental Asset Markets?

Measuring Sovereign Contagion in Europe

Multiplex interbank networks and systemic importance: An application to European data

On the Impact of Leveraged Buyouts on Bank Systemic Risk

Taking the Lead: When Non-Banks Arrange Syndicated Loans

The Influence of Leveraged Buyouts on Target Firms' Competitors

The Effects of Contingent Convertible (CoCo) Bonds on Insurers' Capital Requirements Under Solvency II

Optimal Asset Allocation for interconnected Life Insurers in the Low Interest Rate Environment under Solvency Regulation

Banking Union and the Governance of Credit Institutions - A Legal Perspective

Sovereign Credit Risk, Liquidity, and ECB Intervention: Deus Ex Machina?

How Do Banks React to Catastrophic Events? Evidence from Hurricane Katrina

Revisiting the Narrative Approach of Estimating Tax Multipliers 